\title{
Trajetória de mulheres assistidas em centro de parto normal e sua relação com escolhas terapêuticas
}

\author{
Trajectory of women assisted in birth centers and their relationship with therapeutic choices \\ Trayectoria de mujeres atendidas en centro de parto normal y su relación con las opciones \\ terapéuticas
}

\section{RESUMO}

Objetivo: Conhecer trajetórias de mulheres assistidas em Centro de Parto Normal e a relação com suas escolhas de cuidado no parto e nascimento. Método: Pesquisa qualitativa com 28 mulheres em um Centro de Parto Normal utilizando-se entrevistas em profundidade. Resultados: Emergiram duas grandes categorias. Na primeira, os depoimentos demonstraram o trajeto percorrido para o parto e nascimento e escolhas no cuidado influenciados pelas vivências individuais, impressões da família e pessoas do convívio social. Na segunda, as mulheres reconheceram o Centro de Parto Normal, como um local de práticas diferenciadas no cuidado, sendo um local de aconchego que se assemelha ao lar. Conclusão: Os Centros de Parto Normal e a qualificação dos profissionais da enfermagem obstétrica são estratégias para a mudança do modelo de atenção obstétrica e, também, para que as mulheres possam (res)significar o cuidado que lhes é prestado, possibilitando que recontem suas histórias no processo de parto e nascimento.

Palavras-chave: Parto Humanizado; Parto Normal; Centros de Assistência à Gravidez e ao Parto; Assistência ao Parto; Enfermagem Obstétrica.

\begin{abstract}
Purpose: To know about the trajectories of women assisted in Birth Centers and their relationship with their care choices during and after labor. Method: This is a qualitative research, done with in-depth interviews with 28 women in a Birth Center. Results: Two major categories emerged. First, the statements showed the trajectory taken for labor and labor, as well as choices in care influenced by individual experiences, family impressions and people living together. In the second category, the women recognized Birth Centers as a place of differentiated practices in care, offering coziness that resembles their home. Conclusion: Birth Centers and the qualification of obstetric nursing professionals are strategies to change the model of obstetric care and for women to (re)understand the care provided to them, enabling them to retell their stories in process of labor and labor.

Keywords: Humanized Labor; Natural Labor; Birth Centers; Midwifery; Obstetric Nursing.
\end{abstract}

\section{RESUMEN}

Objetivo: conocer las trayectorias de las mujeres atendidas en los Centros de Maternidad y su relación con sus opciones de cuidado durante y después del parto. Método: Se trata de una investigación cualitativa, realizada con entrevistas en profundidad a 28 mujeres en un Centro de Maternidad. Resultados: Surgieron dos categorías principales. En primer lugar, los enunciados muestran la trayectoria del trabajo y el trabajo, así como las opciones de cuidado influenciadas por las experiencias individuales, las impresiones familiares y las personas que conviven. En la segunda categoría, las mujeres reconocieron a los Centros de Maternidad como un lugar de prácticas diferenciadas en el cuidado, ofreciendo calidez que asemeja a su hogar. Conclusión: Los centros de maternidad y la capacitación de los profesionales de enfermería obstétrica son estrategias para cambiar el modelo de atención obstétrica y para que las mujeres (re) comprendan el cuidado que se les brinda, permitiéndoles volver a contar sus historias en el proceso de parto y parto.

Palabras clave: Parto Humanizado; Parto Normal; Centros de Asistencia al Embarazo y al Parto; Partería; Enfermería Obstétrica.
Débora Lucas Viana Gonçalves ${ }^{1}$

(D) $\underline{0000-0002-6072-1112}$

Síntia Nascimento dos Reis ${ }^{1}$

(1) $\underline{0000-0003-4235-5398}$

Luís Paulo Souza e Souza ${ }^{2}$

(1) 0000-0002-9801-4157

Kleyde Ventura de Souza ${ }^{3}$

(1D) 0000-0002-0971-1701

${ }^{1}$ Hospital Sofia Feldman.

2 Universidade Federal do Amazonas.

${ }^{3}$ Universidade Federal de Minas Gerais.

Autor correspondente:

Débora Lucas Viana Gonçalves E-mail: deboralucasv@gmail.com

\section{Como citar este artigo:}

Gonçalves DLV, Reis SN, Souza LPS, et al. Trajetória de mulheres assistidas em centro de parto normal e sua relação com escolhas terapêuticas. Revista de Enfermagem do Centro-Oeste Mineiro. 2021;11:e4139. [Access___]; Available in: DOI: http://doi.org/10.19175/recom.v11i0.4139 


\section{INTRODUÇÃO}

A trajetória das mulheres na rede de saúde, durante a gravidez e para o parto, pode dizer muito sobre 0 que as motivam a procurarem determinados serviços e o que esperam de cuidados. Em países como Inglaterra, existem políticas públicas consolidadas ao planejamento da mulher em relação ao local de nascimento ${ }^{(1)}$. Nesses países, as mulheres classificadas como de baixo risco podem planejar seu parto, em domicílio, em Centros de Parto Normal ExtraHospitalares que, em inglês, é chamado de Freestanding Midwife Unit, intra ou perihospitalares, chamdos de Alongside Midwifery Unit, todos manejados por enfermeiras obstetras ou obstetrizes, ou, ainda, em unidades obstétricas hospitalares ${ }^{(1)}$.

No Brasil, uma das estratégias adotadas, para qualificar a atenção obstétrica, foi o incentivo à criação de Centros de Parto Normal (CPN), locais que permitem o desenvolvimento das boas práticas no parto e nascimento e o retorno da mulher à centralidade de seu cuidado. Os CPNs foram criados ao atendimento da mulher no Sistema Único de Saúde (SUS) e foram destinados ao atendimento da mulher na gravidez, no parto e no puerpério, além de prestar atendimento humanizado no parto normal sem distócia ${ }^{(2)}$. Esses locais são liderados por enfermeiras obstétricas ou obstetrizes, desde a admissão até a alta e têm como objetivo fornecer cuidado de qualidade, centrado na mulher, no bebê e na família, além de oferecer um ambiente com privacidade $e$ tranquilidade ${ }^{(3)}$.

O CPN se caracteriza como um lugar com valor agregado de baixo custo, mas com alta rentabilidade. Dispõe de um conjunto de elementos que permite à parturiente e seu acompanhante um trabalho de parto ativo e participativo. Apesar de serem implementados desde 1999, no Brasil, o número desses estabelecimentos é reduzido, além do fato de mulheres não terem conhecimento acerca deste serviço que desenvolve práticas que aumentam a satisfação das parturientes, uso restrito de procedimentos invasivos, inserção da enfermagem obstétrica, utilizando-se de práticas baseadas em evidências científicas, diferenciando-se, assim, dos serviços tradicionais de atenção obstétrica ${ }^{(4)}$.

Mesmo havendo uma demanda crescente do parto vaginal no SUS e na Saúde Suplementar, o percentual desse tipo de parto se mantém aquém do desejado, com um aumento de cesarianas e intervenções obstétricas desnecessárias, o que gera consequências à saúde materna e neonatal, em termos de eficácia e efetividade, de utilização de serviços de saúde e dos arranjos de demanda e oferta nos sistemas de saúde ${ }^{(5)}$. Assim, o CPN surge como um equipamento de cuidado, para auxiliar na redução das taxas de cesáreas, pois possibilita a diminuição das intervenções obstétricas ${ }^{(6)}$.

O conhecimento sobre as contribuições dessa ferramenta de cuidado permitirá maior divulgação de suas contribuições na humanização ao parto. É preciso que se conheçam as trajetórias das mulheres que optam por esse serviço, entendendo a necessidade de mudança no modelo obstétrico brasileiro, estabelecendo como visão a necessidade de acelerar o progresso em direção à Cobertura Universal de Saúde e aos Objetivos de Desenvolvimento Sustentável, assegurando a acessibilidade universal, disponibilidade, aceitabilidade, qualidade e o custo efetivo dos cuidados de enfermagem e de obstetrícia para todos, com base nas necessidades das mulheres e da população ${ }^{(4)}$.

Entender qual o significado do cuidado, durante o parto e nascimento, para as mulheres e como elas percebem esse cuidado é importante, uma vez que os significados atribuídos, neste momento, contribuem para determinar as futuras trajetórias pela rede de serviços de saúde, pela construção das próprias convicções e experiências. As mulheres lidam com vários dilemas no seu percurso pela rede de saúde à procura dos cuidados que the sejam mais adequados. Para atender às necessidades de saúde, durante a gravidez, parto e puerpério, elas tecem o itinerário, dentro da rede de saúde, com base em suas convicções que são construídas, ao longo de sua vida; há também a influência de informações que recebem, da qualidade dessas informações e das interações que fazem com a sociedade ${ }^{(7-9)}$. Assim, saber como essas mulheres acessam esses serviços pode facilitar o organização da rede assistencial de saúde, justificando a importância em conhecer seus itinerários terapêuticos e trajetórias.

Os estudos sobre itinerários terapêuticos representam novas possibilidades, para a compreensão dos comportamentos e atitudes das pessoas em relação à busca por cuidado. Utilizando o conceito de um pesquisador americano(10), psiquiatra e estudioso da antropologia médica, essa relação das trajetórias é demonstrada pela intercessão entre os setores informal e profissional. O setor informal (popular na língua 
inglesa), composto pela base individual de cada pessoa, experiências familiares e de vida, meio social, comunidade, é o principal determinante das escolhas do indivíduo. O setor profissional (professional na língua inglesa) é composto pelas instituições de saúde formais, institucionalizadas, com base no modelo biomédico, científico e seus profissionais. Por último, o setor popular (folk na língua inglesa), não profissional ou para profissional, envolve um cuidado holístico, abrangendo corpo, mente, ambiente, moral e espiritualidade ${ }^{(10)}$. O modelo ajuda a entender os múltiplos fatores que vão determinar as escolhas dessas mulheres e como os trajetos se relacionam aos desejos do indivíduo, à cultura e à sociedade. Mesmo não se tratando de um contexto de doença, as mulheres conseguem descrever suas trajetórias para o parto e criar em seu discurso significados para elas.

Considerar aspectos culturais e sociais, bem como a procura de cuidados, podem permitir uma visão mais completa de como as mulheres, dentro de um Centro de Parto Normal, estão se relacionando com o sistema de saúde e com qual lógica estão construindo o seu trajeto, sendo possível entender e propor cuidados condizentes com as suas necessidades reais e de suas expectativas e convicções ${ }^{(9)}$.

Assim, objetivou-se conhecer as trajetórias de mulheres assistidas em um Centro de Parto Normal no Brasil e sua relação com as escolhas de cuidado no parto e nascimento.

\section{MÉTODO}

Trata-se de estudo descritivo, de abordagem qualitativa, realizado com mulheres assistidas no Centro de Parto Normal (CPN) David Capistrano da Costa Filho do Hospital Sofia Feldman (HSF), em Belo Horizonte, capital do estado de Minas Gerais, na região Sudeste do Brasil. O CPN em estudo é peri-hospitalar, tendo sido inaugurado em 2001. Atualmente, é o único do Estado nesta modalidade e tem capacidade de atender 150 partos de baixo risco por mês. A admissão das mulheres pode ser por livre demanda ou por encaminhamento quando o primeiro atendimento é feito no Hospital Sofia Feldman.

A identificação das participantes se deu, a partir de um banco de dados existente composto por 209 puérperas, que deram à luz no CPN, construído para uma pesquisa maior intitulada: "Análise das trajetórias assistenciais de gestantes de risco habitual e suas implicações à qualidade da assistência obstétrica e seu impacto no resultado materno e perinatal", vinculado ao Programa de Educação pelo Trabalho em Saúde (PET) III - Rede Cegonha (2012-2014) -, da Universidade Federal de Minas Gerais. Para o presente estudo, foram selecionadas, intencionalmente, as mulheres residentes no município de Belo Horizonte, totalizando 109 mulheres. Entre elas, foram incluídas aquelas possíveis de serem contatadas, por meio do telefone ou no endereço informado à época do atendimento no CPN, que aceitaram participar desta fase da pesquisa em até seis tentativas de contato e não possuíam desabilidades que prejudicassem a sua comunicação por meio da fala. Assim, a amostra final deste estudo foi de 28 mulheres.

A coleta de dados ocorreu, no período de maio a julho de 2014, utilizando-se de entrevistas em profundidade com a seguinte questão norteadora: "Conte-me como foi a sua busca por atendimento durante o pré-natal, até a sua chegada à maternidade e o nascimento do seu filho". Destaca-se que, previamente à coleta final, foi realizada uma entrevista com a finalidade de testar o roteiro da entrevista, não tendo sido verificada a necessidade de modificações no instrumento.

As entrevistas tiveram duração média de 7 (sete) minutos, as pacientes participantes estavam em intervalo de pós-parto entre 3(três) a 11 meses. Vale ressaltar que as 81 do total de 109 não participaram do estudo, indisponibilidade de contato telefônico. Além disso, a entrevista de caráter pré-teste foi realizada com as 3(três) primeiras pacientes contatadas da amostra final das 28 participantes.

No momento das entrevistas, que ocorreram nos domicílios das participantes, com as mulheres sempre acompanhadas de seus filhos, coletaram-se informações que permitiram a caracterização da população estudada. As falas foram gravadas e transcritas na íntegra e, em seguida, foram revisadas quanto à acurácia dos áudios pelos pesquisadores.

Neste estudo, utilizou-se como referencial teórico o conceito de sistema de cuidado de saúde ${ }^{(10)}$, que demonstra uma articulação sistêmica entre os diversos elementos ligados à saúde, às doenças e aos cuidados, abrangendo a atitude do indivíduo perante essas situações e os fatores que vão determinar as escolhas terapêuticas. Desta forma, buscou-se entender os cuidados condizentes com as necessidades reais 
das mulheres, suas expectativas e convicções. Como referencial metodológico, para a análise de dados, utilizou-se a análise temática de conteúdo de Bardin ${ }^{(11)}$, buscando identificar os itinerários das mulheres, no processo de parto e nascimento, bem como as escolhas e estratégias utilizadas por elas na busca por cuidado nesse momento singular de suas vidas e da busca por atendimento nos serviços de saúde na rede de atenção. As falas permitiram a elaboração de duas grandes categorias.

A pesquisa foi aprovada pelos Comitês de Ética em Pesquisa com Seres Humanos da Secretaria Municipal de Saúde de Belo Horizonte (CAAE 13338713.9.0000.5132), da Prefeitura de Belo Horizonte (número 381.882) e do Hospital Sofia Feldman (número 324.262). Vale destacar que foram cumpridas as recomendações da Resolução 466/2012 do Conselho Nacional de Saúde e assinatura de TCLE. Os nomes das participantes foram substituídos por "Marias". O local de prestação dos serviços de saúde prestados às pacientes foi identificado, de acordo com a sua denominação na rede de serviços de saúde do SUS, sem mencionar seus nomes, preservando o anonimato.

\section{RESULTADOS}

Em relação à caracterização das mulheres entrevistadas, a idade variou entre 17 e 40 anos. Maior parte se declarou casada, de cor parda, escolarizada (ensino médio completo) e multíparas. Sobre as ocupações, a maioria delas declarou ser "do lar".

Os enunciados foram agrupados de acordo com a sua similaridade e compuseram duas grandes categorias: 1) As (res)significações das mulheres no percurso dos partos e nascimentos baseadas na mulher, na familia e nas relações com a comunidade; 2) As mulheres e a relação com a rede de serviços de saúde: o Centro de Parto Normal enquanto potente local de cuidados e de concretização das escolhas, as quais serão detalhadas e exemplificadas com as falas a seguir. O debate/discussão dos significados de cada fala é feito, posteriormente, na seção de Discussão.

\section{As (res)significações das mulheres no percurso do parto e nascimento baseadas na mulher, na família e nas relações com a comunidade}

Essa categoria foi elaborada, a partir dos depoimentos das mulheres, em relação ao trajeto percorrido para o parto e nascimento e escolhas no cuidado influenciadas pelas vivências e experiências individuais, posicionamento da família e opiniões de outras pessoas fora do contexto familiar. São elementos que vão influenciar de forma significativa nas escolhas das trajetórias nesse momento de suas vidas. Segundo o modelo de Sistema de Cuidado de Saúde, é da esfera individual, social e comunitária que vão se originar as principais decisões sobre o cuidado à saúde ${ }^{(10)}$.

Quando a mulher já tem alguma perspectiva do que quer, ela percorre seu caminho em busca de fundamentar suas convicções e alcançar o cuidado perspectivado. As mulheres reiteram o desejo pelo parto natural, humanizado. Conseguem refletir em relação à dor no parto e reforçam a convicção de um parto mais fisiológico. E isso pode ser observado nas falas a seguir:

"Foi porque eu não queria ganhar anestesia, num queria de qualquer jeito, só se necessitasse mesmo, então lá [hospital da pesquisa] eu tive esse apoio, elas [enfermeiras obstétricas] iam me ajudar independente que eu tivesse lá no meu íntimo que ia doer, eu sei que dói, aí eu gostei por isso, eu escolhi lá por isso, que é parto humanizado. Fui eu, minha mãe, meu marido, meu irmão. Foi todo mundo!". (Maria Aparecida)

"Eu pensava assim: 'Eu quero um parto normal, mas com analgesia". Eu tinha muito medo da dor do parto, ele nasceu bem natural, bem, sem nenhuma intervenção. Eu fiz o plano de parto, meu plano de parto foi seguido à risca, e as enfermeiras que me assistiram foram maravilhosas, nenhum momento me senti insegura". (Maria do Carmo)

Tanto os relatos acima quantos os seguintes demonstram que essas mulheres estão refazendo suas convicções sobre qual tipo de parto e que cuidado desejam nesse momento, possibilitando (re)significações em relação ao parto. Para tanto, buscam informações que vão sustentar o seu desejo de cuidado:

"Eu tentava tirar minhas dúvidas [em relação ao parto natural]. Eu tinha medo do parto natural. Eu sei que é melhor pra saúde. É bem melhor. Adorei!Não levei anestesia nenhuma pra mim ganhar. Mas foi eu mesma que pedi. Foi uma escolha minha mesmo". (Maria Aparecida)

"Porque lá [hospital de referência do CPN] tem parto normal e eu queria natural! Eu queria parto natural, eu queria sem intervenção nenhuma. Então, por isso também que me fez procurar lá, 
porque normal por normal cê pode ganhar em qualquer lugar. Eu queria um diferencial. Queria natural. (Maria Antônia)

"E eu não fiz uma escolha desinformada. Pelo contrário eu fiz uma escolha muito bem informada". (Maria Helena)

"Eu sempre tive na minha mente, desde criança sempre pedi a Deus, eu quero um parto natural, passei minha vida inteira imaginando isso. Eu nunca quis ter uma cesárea. Nas primeiras contrações, subi escada, descia escada, eu ia pro chuveiro, agachava, levantava, isso tudo porque eu já tinha visto na internet, já tinha me informado". (Maria de Lourdes)

Destaca-se das falas dessas mulheres as frases: "o que eu quero"; "foi eu mesma quem pedi"; "foi uma escolha minha mesmo". São expressões que revelam suas escolhas em relação ao cuidado que desejam. Contudo outro aspecto que aparece como influenciador nas escolhas foi a família, como observado nas falas:

"Eu nunca tinha ido não [no hospital da pesquisa]. Depois que a minha mãe ganhou minha irmã lá, eu fui visitar e gostei muito de lá". (Maria da Penha)

"Foi escolha minha; a madrinha do meu primo [falou], que lá era um local bom, só que eu não conhecia eu fui mais por causa disso. Minha familia já conhecia e falou assim: 'ganha lá'. Eu falei assim: 'ah eu vou lá sim'". (Maria Rita)

"Eu escolhi porque minhas colegas tudo falou que lá [Casa de Parto] era bom. Minha irmã mesmo teve o menino dela lá. Eu sempre ia lá visitar, chegou o segundo filho aí eu fiz minha escolha mesmo de ir pra casa de parto". (Maria Aparecida)

Como observado, o parto se torna um evento familiar e comunitário, e a opinião desse círculo social será importante para as escolhas dessas mulheres. Esse é o setor que mais vai influenciar e balizar as emoções das mulheres durante a gravidez, parto e puerpério. $O$ apoio desse núcleo se apresenta como fundamental para a afirmação das conviç̧ões e direções para esse rito na vida das mulheres. A aprovação da família em relação às escolhas dessas mulheres é uma segurança. Algumas que tinham suas convicções em relação ao parto tiveram que fazer todo um trabalho de argumentação com seus familiares, essencial para sustentar suas escolhas do trajeto a ser feito.

"O meu esposo é de uma família que só tem filho de cesárea e eu tive que fazer um trabalho de convencimento do meu esposo pra ter o parto normal". (Maria Helena)

"Eu trabalhei num hospital, então eu sempre conheci o trabalho [do hospital da pesquisa], eu já conhecia pelo pessoal que trabalhava comigo, eu trabalhava numa maternidade também. A minha mãe que não conhecia, ela tava muito receosa, porque infelizmente sempre têm pessoas pra falar mal, então, eu chamei ela pra gente ir lá [hospital da pesquisa] fazer uma visita, pra ela conhecer, porque eu já conhecia. Fomos lá, o pessoal da ouvidoria recebeu a gente e mostrou a maternidade e a casa de parto que era o meu maior interesse. Ela [mãe da entrevistada] ficou super tranquila, gostou demais, fala bem agora pra todo mundo". (Maria Lúcia)

Estas mulheres precisam construir seu discurso em defesa do que acreditam e, por isso, buscam informações de qualidade. Observa-se um movimento grande e diverso nessa busca, principalmente, por meio de redes sociais.

"Eu conheci assim pela internet [hospital da pesquisa], por indicação [de um grupo de apoio à gestante] também, que é esse grupo de apoio à gestante, grupo de incentivo ao parto normal, e eu li bastante pela internet. (Maria do Carmo)

"Eu tinha muita vontade de ter o parto normal. Mudei pra Belo Horizonte há pouco tempo, foi no início do ano passado, eu já tava grávida. Aí eu comecei a procurar na internet e descobri grupos de apoio Igrupos de apoio às gestantes; lá eu fui orientada, me encaminhou [o grupo de apoio às gestantes] pra parteira, enfermeira obstetra mais famosa que tem". (Maria Cristina)

Outra fala sobre um "discurso hegemônico" e, como isso influencia nas escolhas das mulheres, relaciona-se à cultura de que as mulheres são "fracas", é embutida no discurso de alguns profissionais que se propaga na sociedade. Outro aspecto expresso pela participante refere-se ao entendimento de que o tipo de parto que a mulher terá é uma escolha. (Maria)

"Você não convence ninguém a ter parto normal. Isso é escolha, porque, se a mulher quiser achar na literatura, no senso comum, vinte motivos pra não se ter um parto normal, ela acha, 
cinquenta ela acha. Pra se ter uma, uma cesárea, ela acha. Então é escolha". (Maria Helena)

Entre as participantes, algumas (res)significaram o momento em que viveram, enfatizando dificuldades, mas, ao contrário do senso comum, conseguiram (re)significar suas experiências com ensinamentos para suas próprias vidas:

"Eu peguei a última gota de força que eu tinha e fiz aquela força, eu fiquei elástica. Essa criança nasceu, parecia final de copa do mundo! É uma experiência única você dar à luz o seu filho, e eu tenho muito orgulho de falar e foi difícil". (Maria de Lourdes)

"Foi isso, a gente ressignifica as coisas. Foi uma catarse, foi uma experiência assim muito louca, me levou ao encontro da minha natureza mamífera mesmo, a leoa que existe dentro de mim. Hoje, eu falo que eu escolheria essa experiência de novo". (Maria Beatriz)

Elas se sentem mais fortalecidas como mulher, porque thes foi ofertado cuidado, que fortaleceu protagonismo no parto. Desse modo, permitirem-se viver um momento profundo, como o parto, faz-lhes criar convicções próprias. A seguir, as falas que confirmam as afirmações:

"Eu até falo pra outras pessoas que tá grávida que foi o único lugar assim que eu senti segurança [hospital da pesquisa]". (Maria Vitória)

"Eu acho que [CPN] foi determinante; fui muito bem cuidada lá. Eu sei que minha filha nasceu, porque eu tirei um dia inteiro pra cuidar dela, com práticas que ela se sentiria que tava na hora que podia vim, que eu tava inteira pra ela". (Maria Helena)

Mesmo as mulheres que não conheciam o CPN ou tinham receio do parto natural conseguiam refletir sobre a experiência e lidar com seus medos. Baseando-se nas próprias vivências, elas refazem suas convicções e desejos.

"Ganhei ele não foi no hospital, foi na casa de parto. Eles me deram essa opção. De início eu fiquei meio receosa porque eu imaginava outra coisa. Fiquei com medo! Parto natural não quero. Só que, assim, foi uma experiência que se eu tivesse que passar de novo, eu passaria do mesmo jeito, no mesmo lugar. Superou tudo". (Maria Alice)

"Me me perguntou [profissional de saúde] se eu queria ir pra casa de parto. Aí como eu não sabia eu perguntei que era a casa de parto? Ela [profissional de saúde] falou que era um parto natural, que não tinha anestesia, nem nada. Eu falei que eu queria ir pra lá". (Marinha da Penha)

As mulheres e a relação com a rede de serviços de saúde: o Centro de Parto Normal enquanto potente local de cuidados e de concretização das escolhas

Essa categoria foi construída com base nos relatos das mulheres ao reconhecerem O CPN como um local de práticas diferenciadas no cuidado de enfermagem no parto e nascimento.

Neste estudo, percebeu-se que nem sempre essas mulheres seguem o que é estabelecido pela rede, perfazendo trajetos de acordo com suas necessidades em saúde, grau de informação que possuem e influência das pessoas de seu meio social ou não. Além disso, essas mulheres têm buscado caminhos que não estão contemplados na rede de saúde. Mulheres que tinham a opção de terem seus filhos na rede privada têm procurado o Sistema Único de Saúde (SUS), público, universal e gratuito, por reconhecerem nele possibilidade de atenção em saúde, segundo o que elas acreditam ser o melhor para elas e seus bebês.

"Eu já tinha uma escolha clara que eu queria ter filho [no hospital da pesquisa], porque pra mim eu não tô buscando hotelaria, eu tô buscando qualidade da assistência. Precisei convencer o meu esposo, que foi conhecer as maternidades privadas. Por último eu falei com ele: "então agora nós vamos lá [no hospital da pesquisa], que é a minha escolha. Eaí, foi o lugar que ele mais gostou que ele sentiu mais acolhido". (Maria Helena)

"Fiz todo meu pré-natal pelo SUS, porque eu acho que são poucas as políticas públicas nossas que a gente pode confiar de olhos fechados. Mas eu fiz questão de privilegiar mesmo a questão do SUS e mesmo porque também a gente tava em transição, não tinha plano de saúde na época então. Sabe quando cê nem considera outra possibilidade mesmo? Eu num considerei outra possibilidade. Questão da referência e desejo". (Maria Beatriz)

Essas mulheres procuram no SUS um cuidado que atenda a suas expectativas, dando menor valor aos aspectos relativos à estrutura física. As mulheres têm retornado para o SUS e citam as políticas públicas no campo da atenção obstétrica como um fator que qualifica a qualidade e segurança no parto. Contudo outras falas 
demonstram que a falta de carência, nos planos de saúde particular, obriga as mulheres a modificarem seus percursos na rede de atenção à saúde; elas vão criando alternativas para garantir o cuidado perspectivado.

"Eu descobri eu nem pensei em marcar no posto nem nada, pois eu já tinha acompanhado minha mãe que ganhou no particular, então: "vô no particular". Fiz até os 6 meses normal no particular, só que até então meu plano não cobria parto, que é a carência. Eu comecei a ver parto humanizado, eu comecei a fazer no posto, só que lá o ginecologista era muito difícil ter horário, e pra fazer os exames era muito cedo". (Maria Antônia)

$\mathrm{Na}$ declaração das mulheres, o CPN ou a Casa de Parto é realçado como um local de aconchego que se assemelha ao lar; elas referem a ele como um ambiente familiar e seguro. O local seria a concretização que elas desejavam para o nascimento de seus filhos e, por isso, fizeram a trajetória em busca desse cuidado, que as fortalecesse como protagonista. As falas, a seguir, confirmam essa afirmativa:

"Em questão de atenção, elas [enfermeiras obstétricas] perguntam se tem alguma posição que a gente acha mais agradável. Vai dando aquele apoio emocional bacana". (Maria Inês)

"Eu tinha gostado muito porque eu achei lá bonito, aconchegante e ainda tava servindo canjica pras recém paridas. A casa de parto era a primeira opção porque é mais legal. É um ambiente aconchegante, aquela cozinha, aquela mesa no meio do caminho, o atendimento das pessoas todas que receberam lá e tudo é uma coisa muito familiar e parece caseira". (Maria Cristina)

Algumas dessas mulheres revelam o desejo imediato pelo CPN por conhecimento prévio. Portanto fizeram escolhas que as direcionasse para esse local de nascimento. O acompanhamento e cuidado direto e constante das enfermeiras obstétricas e uma equipe de enfermagem preparada são vistos também como aspecto importante no CPN. A seguir, uma das falas que retrata esse cuidado.

"Então, fiquei no quarto sozinha, só com elas [enfermeiras] assim, aí eu senti uma paz também, sabe assim, teve dor é claro, mas foi tudo naturalmente". (Maria Joana)

Muitas dessas mulheres não conheciam o CPN como local de nascimento e, atualmente, não existe uma referência formal na rede de saúde para esse local. Em sua grande maioria, para o encaminhamento ao CPN, as mulheres são avaliadas primeiro no hospital pesquisado. Alguns relatos demonstram temor a ir para esse local por temor da dor no parto; outras estavam dispostas a passar pela experiência, como na fala que se segue:

"Tinha ouvido falar que quando cê vai pra lá [hospital da pesquisa] eles tentavam muito que você ganhasse na casa de parto. Só que eu não sabia como que era até então. Eu fui, desci, gostei, meu esposo também gostou. Aí a gente optou por ganhar lá mesmo". (Maria Paula)

A abordagem dos profissionais em relação ao CPN faz uma diferença na escolha dessas mulheres, especialmente, pelos esclarecimentos quanto ao modelo de cuidado preconizado nesse tipo de serviço. O acompanhamento e o cuidado direto e constante das enfermeiras obstétricas são vistos também como aspecto importante na Casa de Parto.

"Gostei! Nó, ótima, muito boa! Lá é tranquilo [CPN], as pessoas respeitam a gente, enfermeira muito educada". (Maria Aparecida)

"Pra Casa de Parto, a menina que ficou comigo lá, a enfermeira, gente ela era uma gracinha! E toda hora ela tava lá, medindo minha pressão, conversando comigo. Então, isso me passou uma tranquilidade, que eu consegui ter o parto normal por causa disso. Porque eu acho que se eu tivesse ficado pra lá jogada eu não teria conseguido. Porque precisa de um acompanhamento; cê fica naquela aflição, naquela ansiedade. A mocinha [enfermeira] que ficou comigo ela foi super tranquila, ela me acalmou conversava comigo, fazia massagem. Nossa! Foi muito tranquilo". (Maria Rita)

"Foi uma experiência de muito amor, de muito carinho, de pessoas que nunca tinham me visto na vida, gente. Não estou falando de uma irmã minha, de uma prima minha que me ajudaria com certeza, por amor e por vivência. Eu estou falando de pessoas que nunca me viram na vida, que dedicaram todo o amor que elas tinham ali na hora, todo cuidado que elas tinham ali na hora comigo, com minha filha e com meu marido. Eu não sei se minhas amigas, se meus parentes, eu não sei se me dedicariam a atenção que a equipe me dedicou. Eu me emociono porque foi dessa maneira, com esse calor que elas me receberam". (Maria Beatriz) 


\section{DISCUSSÃO}

Com o intuito de valorizar a discussão dos dados e facilitar a sua compreensão, esta etapa foi descrita de acordo com as categorias já apresentadas. Assim, os dados conversam entre si, confluindo no objetivo de conhecer a trajetória de mulheres assistidas em um CPN e sua relação com as escolhas de cuidado no parto e nascimento.

A trajetória dessas mulheres demonstra a busca por cuidados, influenciadas pelas próprias convicções, construção de experiências e vivências individuais, família, sociedade, comunidade. A esses fatores, somam-se a busca pelo cuidado holístico e as ofertas de serviços das instituições formais de saúde e seus profissionais. Todos esses elementos interagem entre si num processo dinâmico que vai influenciar as escolhas das mulheres no parto e no nascimento, definindo-lhes o trajeto na rede de saúde. O sistema de cuidado de saúde deve ser consideradopela relação entre as convicções pessoais, relacionamentos sociais e valores culturais com os serviços de promoção da saúde. Esse complexo e amplo sistema orgânico e vivo é o representado no modelo de Sistema de Cuidado de Saúde ${ }^{(10)}$. No caso deste estudo, colocando em relevo a centralidade das mulheres relativas às suas experiências de parir e como as dimensões social e cultural podem influenciá-las, depreende-se delas (re)significações de experiências/vivências individuais, possibilitando uma maior compreensão do contexto.

Neste estudo, o CPN foi revelado como um local de nascimento que permite a concretização do desejo de ter um cuidado contínuo, seguro, singular, que respeite a fisiologia do corpo da mulher, oportunizando vivências semelhantes a outros cenários. No Reino Unido, as mulheres são orientadas, desde o pré-natal, sobre as possibilidades de locais de nascimento. Segundo The National Institute for Health and Care Excellence (NICE), mulheres de baixo risco têm a oportunidade de escolher o local de nascimento ${ }^{(1)}$. $\mathrm{Na}$ Inglaterra, a decisão em relação ao local de nascimento normalmente é planejada junto com a família. As mulheres são orientadas, ainda, sobre como se configura o baixo risco na gestação, recebem explicações detalhadas sobre todos os tipos de local de nascimento, são informadas sobre as pesquisas e estatísticas sobre os locais, as possíveis intercorrências que podem acontecer e sobre as práticas adequadas para o parto. Têm, ainda, acesso aos resultados maternos e fetais, em relação a cada local de nascimento, para que tenham discernimento sobre a segurança de suas escolhas ${ }^{(12)}$. Portanto recebem informações de qualidade e fazem parte do processo decisório do seu cuidado.

O CPN é um local que carrega um significado simbólico de renovação das práticas obstétricas, com paradigma próprio e necessário para a transformação da cultura predominante nas instituições que prestam assistência ao parto ${ }^{(11)}$. Em alguns países, os Birth Centers liderados por midwives são locais de nascimento que corresponderiam aos Centros de Parto Normal no Brasil. As midwives são profissionais dedicadas ao cuidado da mulher durante a gravidez, o parto e o puerpério e ao recém-nascido, baseada em evidências científicas, em uma filosofia de cuidado que respeite e garanta diretos, à semelhança das enfermeiras obstétricas ou obstetrizes, no Brasil.

Neste estudo, ainda, algumas mulheres não conheciam O CPN e se surpreenderam com o cuidado prestado. Parte deste desconhecimento pode ser atribuída ao não referenciamento formal na rede de saúde para o CPN desta pesquisa. As mulheres são admitidas no hospital, onde, de acordo com o risco, é-lhes oferecida a possibilidade de irem para o CPN. A relação com esse local de nascimento muda, quando as mulheres já o conhecem, por experiências anteriores ou informações. Nesse caso, elas mesmas manifestam, durante a avaliação no hospital, o desejo de ir para o CPN.

Os relatos das mulheres confirmam as propostas sustentadas para um CPN, ao expressarem um reconhecimento deste local como um ambiente de concretização para o que desejavam para o parto: familiar, de privacidade, seguro, aconchegante, de suporte contínuo que as respeite nas suas singularidades. A privacidade oferecida também é uma característica valorizada por essas mulheres, evidenciando o caráter íntimo e familiar do CPN. Evidenciam características de um ambiente e, de certo modo, de cuidar que se distingue de outros espaços de nascimento, como os tradicionais serviços de maternidades, especialmente aqueles, ainda predominantes no Brasil, que, ao praticarem uma assistência fragmentada, hierarquizada e marcada pela violência obstétrica (VO), afetam as mulheres de distintas formas, refletindo as iniquidades na assistência ao parto e nascimento ${ }^{(13)}$. Nesta perspectiva, a ampliação de CPN, ainda em número reduzido no Brasil, configura-se numa importante 
estratégia para a superação do atual e hegemônico modelo obstétrico brasileiro.

O cuidado constante, o carinho, a atenção das enfermeiras(os) obstétricas e da equipe do CPN são ressaltados nos depoimentos. A segurança na assistência e o preparo é outra característica atribuída aos profissionais do CPN. As enfermeiras obstétricas afirmam a importância de persistirem em prestar uma assistência prudente e responsável, de acordo com o princípio de fazer valer os direitos das mulheres, atendendoIhes os anseios e as necessidades de saúde ${ }^{(14)}$.

O cuidado da enfermagem obstétrica em um CPN deve ser pautado pelos princípios da humanização, da ética, além do uso das tecnologias apropriadas. Em estudo qualitativo realizado na Noruega, as mulheres também ressaltaram que as midwives dedicaram tempo com elas tanto no pré-natal quanto no parto. Isso foi de extrema importância ao esclarecimento de dúvidas, pois permitiu que elas se sentissem seguras, confiantes e relaxadas ${ }^{(15)}$. No mesmo estudo, destacou-se que a presença continua da midwife - de preferência a mesma - também promove segurança e confiança às mulheres, as quais, dessa forma, sentem-se cuidadas ${ }^{(15)}$.

O cuidado da enfermagem obstétrica deve estar pautada nas evidências científicas e promover conforto, segurança, satisfação, como foi evidenciado nos relatos dessas mulheres. 0 cuidado das midwives contribui para que as mulheres tenham um parto natural e uma experiência positiva. O fortalecimento dessas mulheres no parto permite uma perspectiva positiva à promoção da saúde em longo prazo ${ }^{(1)}$. 0 modelo de cuidado conduzido pela enfermeira(o) obstétrica(o) ou obstetriz parte da premissa de que a gestação e o parto são acontecimentos normais da vida ${ }^{(16)}$. O cuidado prestado por esses profissionais contempla a monitorização do bemestar físico, emocional e espiritual da mulher e de sua família durante o ciclo gravídico-puerperal ${ }^{(16)}$.

O cuidado da enfermagem obstétrica pode estimular a autonomia da mulher para que ela exerça seu direto de parir com segurança e prazer. Esse aspecto demonstra o poder político e emancipatório do cuidado da enfermagem obstétrica $^{(16)}$. Nessa perspectiva, a enfermagem obstétrica no Brasil encontra-se em um momento histórico e se revela um dos agentes de transformação do modelo ainda vigente, que demanda, em virtude disso, a formação de recursos humanos que atendam a essas expectativas. A assistência conduzida por enfermeiros obstetras ou obstetrizes contribui para garantir uma assistência humanizada e evitar intervenções desnecessárias ${ }^{(15)}$, podendo servir de modelo para outras instituições, especialmente, as hospitalares. O incentivo e a criação de novas estruturas assistenciais, como Centros de Parto Normal e qualificação dos profissionais de saúde, especialmente, de enfermeiras(os) obstétricas, obstetrizes e da equipe de enfermagem, são caminho mais seguro para uma mudança do modelo de atenção obstétrica no país.

Há uma mobilização de ações políticas no Brasil, na discussão sobre mudanças no modelo brasileiro de atenção ao parto, com a adoção de práticas e protocolos baseados em evidências científicas, objeto de estudos recentes no país ${ }^{(17-18)}$. Além disso, as mulheres estão questionando o sistema de saúde formal e seus profissionais na assistência no ciclo gravídico puerperal.

Nesse sentido, os dados demonstraram, também, quão importante é contribuir para a construção de convicções, em relação ao parto, por meio de experiências já vividas e de informações adequadas. Algumas mulheres fazem sua trajetória, durante a gravidez e o parto, baseando-se no que elas desejam e não no que é regulado pela rede de saúde. Outro resultado observado é o relato de outras mulheres, de experiências positivas em relação ao local de nascimento e parto, promovendo mais segurança nas escolhas durante esse período. Em pesquisa multicêntrica realizada no Brasil, as mulheres que desejavam ter o parto vaginal expressavam esse desejo, porque acreditavam que esse tipo de parto é mais fisiológico, natural e elas teriam uma recuperação mais rápida ${ }^{(19)}$. Tais convicções corroboram aquelas mencionadas nos relatos das mulheres da pesquisa em relação aos desejos sobre o parto.

No momento do nascimento é que se iniciam os cuidados mais fundamentais, para manter e acompanhar a vida da mãe e da criança que acaba de nascer ${ }^{(20)}$. Ser cuidado, cuidar-se e cuidar são conjugações que envolvem importantes passagens da vida, o que configura a indispensável necessidade dos cuidados. Para o nascimento, foram gerados saberes, criando-se hábitos na sociedade com características culturais, imersos em representações simbólicas, muitas vezes, impregnados de ritos $^{(16)}$, exigindo, pois, questionamentos sobre o instituído. Portanto, no cuidado centrado na mulher, deve-se considerar, 
também, os contextos familiar, social e cultural para atender de forma mais completa às necessidades de saúde ${ }^{(19)}$.

A racionalização da ciência excluiu os saberes empíricos da prática do cuidar durante o nascimento. Os saberes empíricos utilizados nos cuidados passaram a ser encarados como supersticiosos, e o entendimento do parto como rito de passagem passou a ser ignorado, desvalorizado. A perda desse tipo de conhecimento na prática do cuidar trouxe graves prejuízos para as mulheres, retirando o cuidado da sua significação simbólica A prática do cuidar é uma arte de pleno direito. As mulheres têm retomado a busca do seu protagonismo no parto, em que ela e sua família participam ativamente do cuidado em torno deste evento(21).

Os resultados apresentados mostraram uma procura por informações e conhecimento no período da gestação. As mulheres relataram diversas formas para adquirir as informações: grupos de mulheres, feiras, internet, entre outras. Os movimentos de mulheres e Organizações Não Gornamentais (ONG) aparecem como mecanismos de informação e conhecimento potentes no retorno da mulher como participante ativa do seu cuidado no parto ${ }^{(22,23)}$. Neste estudo, as mulheres enalteceram os movimentos que fizeram parte da trajetória de algumas delas. Todas essas iniciativas demonstram que as mulheres estão se mobilizando, e uma das importantes características desses movimentos é a troca saudável e democrática de conhecimento e experiências entre elas ${ }^{(24)}$.

Nos resultados deste estudo, percebe-se uma procura das mulheres em ter seu parto no SUS, mesmo aquelas que têm planos privados de saúde, por acreditarem que ali serão atendidas nas suas expectativas de cuidados no parto. A sociedade, de modo geral e as mulheres, em particular, devem reaprender a ocupar seu lugar no domínio dos cuidados e, dessa forma, reassumir como protagonista no sistema de saúde ${ }^{(8)}$. O setor profissional deve escutar os usuários de saúde e tentar entender-Ihes os anseios de cuidado(10).

Outro resultado observado é o de experiências positivas, em relação ao local de nascimento e parto, promovendo mais segurança nas escolhas durante esse período. Portanto o incentivo e a criação de novas estruturas assistenciais, como os CPN e qualificação dos profissionais de saúde, em especial, de profissionais da enfermagem obstétrica, são estratégias para uma mudança do modelo de atenção obstétrica no país e, também, para que as mulheres possam ressignificar o cuidado que thes é prestado, possibilitando que recontem suas histórias no parto e nascimento ${ }^{(24)}$.

Em detrimento destes resultados, importante pontuar que, na cidade onde se realizou o estudo, uma das grandes capitais brasileiras, uma maternidade construída desde 2009, com potencial para funcionar como um CPN, por atender requisitos propostos pela Organização Mundial de Saúde (OMS) e pelo Ministério da Saúde (MS), mantém suas portas fechadas, em que pese todos os benefícios que esse tipo de serviço pode oferecer: melhora de indicadores perinatais; local de referência para um modelo de cuidado e de formação profissional, entre outras. Essas justificativas não têm sido suficientes para colocar em funcionamento um equipamento de saúde com número reduzido num país que tem três milhões de nascimentos/ano e altas taxas de cerianas desnecessárias ${ }^{(25)}$.

Nesta perspectiva, coloca-se em tela a necessária criação e fortalecimento de espaços como CPN, que por sua filosofia trazem em si práticas renovadas de cuidados, com inclusão das mulheres como protagonistas do processo de parir, uma das formas para a superação do modelo obstétrico brasileiro, que, embora com avanços reconhecidos, há nele muito o que se avançar ${ }^{(26)}$.

Os dados decorrentes das restantes entrevistas revelarão, com certeza, novas e diversificadas narrativas e gramáticas da(s) doença(s) que colocarão em relevo a centralidade dos indivíduos e do seu posicionamento social e cultural nas várias dimensões relativas à experiência da doença.

O importante é que se crie um espaço, para novas práticas e cuidados, tanto para profissionais da saúde quanto para usuários/clientes, na construção de projetos terapêuticos mais abrangentes que possam superar a dicotomia do modelo biomédico hegemônico. As práticas/cuidados redimensionariam seus limites incluindo o usuário/cliente como sujeito ativo no seu cuidado e como protagonista no seu processo de adoecimento. 


\section{CONSIDERAÇÕES FINAIS}

O presente estudo buscou conhecer trajetórias de mulheres assistidas em Centro de Parto Normal (CPN) e a relação com suas escolhas de cuidado no parto e nascimento. Nesse sentido, as duas categorias, aqui apresentadas, agem em complementaridade na demonstração de como as mulheres significam o cuidado recebido em um CPN o olhar ampliado sobre a organização do sistema de cuidado de saúde, relacionando a construção das conviç̧ões individuas com a utilização dos serviços de saúde. É urgente a compreensão do sistema de saúde, para adequá-lo às reais necessidades de saúde da população, por meio da sensibilidade de como ele se organiza e como se configura a busca por cuidados de uma população.

As mulheres têm a família, a sociedade e a comunidade organizadas sob um simbolismo cultural, que é o reduto da primeira escolha por cuidados. Os depoimentos apresentados reforçam o caráter familiar e social do parto e do nascimento, além de revelar como as mulheres estão agindo para seu retorno ao protagonismo no parto. Os movimentos de mulheres, nas redes sociais e com a política, têm favorecido esse processo. As mulheres têm percebido qual é o melhor cuidado para elas. Somente as mulheres como atores sociais ativos serão capazes de modificar o ambiente de parto, e esse movimento já está sendo realizado. Nesse cenário, O CPN sobressaiu como um local de cuidado capaz de oferecer uma assistência, de acordo com os reais desejos dessas mulheres, destacando-se como um local de aconchego, familiar, seguro, em que suas necessidades são atendidas de forma integral.

Seguindo o propósito de alcançar o entendimento do significado do cuidado, durante o parto e nascimento para as mulheres e como elas percebem esse cuidado, pode-se dizer que o CPN mostrou-se um local que promove as boas práticas ao parto e ao nascimento, e a enfermagem obstétrica tem permitido a garantia de tais práticas. O cuidado contínuo e seguro prestado pelo profissional dessa área tem proporcionado experiências positivas em relação ao parto. A visão de rede e a escuta sensível das mulheres podem predizer muito sobre o tipo de cuidado que devem ser prestados a elas.

Este estudo limitou-se a uma instituição. Recomenda-se a realização de mais estudos, utilizando o referencial teórico apresentado, tendo em vista que é um referencial pouco explorado, mas que auxilia fortemente no entendimento dos fatores que determinam a escolha por cuidados dos sujeitos nos serviços de saúde e como seus trajetos (com suas influências) influenciam nessa escolha. Por fim, há necessidade de outros estudos, em ambientes como os CPN, pois conhecer as contribuições dessa ferramenta, pautado no cuidado da enfermagem na visão das mulheres possibilitará a divulgação e o desenvolvimento de ações humanizadas no parto, políticas de saúde e diretrizes vigentes, buscando a mudança do modelo obstétrico.

\section{REFERÊNCIAS}

1 - National Institute for Health and Care Excellence (NICE). Intrapartum care for healthy women and babies. Reino Unido: Nice; 2014 [citado em 14 dez 2020]. Disponível em: https://www.nice.org.uk/guidance/cg190/resourc es/intrapartum-care-for-healthy-women-andbabies-pdf-35109866447557

2 - Brasil. Ministério da Saúde. Portaria no 985, de 5 de agosto de 1999. Cria o Centro de Parto Normal (CPN) no âmbito do Sistema Único de Saúde (SUS). Brasília: Ministério da Saúde; 1999 [citado em 14 dez 2020]. Disponível em: http://www.cvs.saude.sp.gov.br/zip/Portaria\%20G M\%20MS\%20n\%C2\%BA\%20985,\%20de\%2005ago 99.pdf

3 - Brasil. Ministério da Saúde. Portaria no 11, de 7 de janeiro de 2015. Redefine as diretrizes para implantação e habilitação de Centro de Parto Normal (CPN), no âmbito do Sistema Único de Saúde (SUS), para o atendimento à mulher e ao recém-nascido no momento do parto e do nascimento, em conformidade com o Componente Parto e Nascimento da Rede Cegonha, e dispõe sobre os respectivos incentivos financeiros de investimento, custeio e custeio mensal. Brasília: Ministério da Saúde; 2015 [citado em 14 dez 2020]. Disponível em: https://bvsms.saude.gov.br/bvs/saudelegis/gm/20 15/prt0011 0701 2015.html

4 - Mamede MV. Força de trabalho da enfermagem e obstetrícia e os novos Objetivos de Desenvolvimento Sustentável (2016-2030). Rev Rene 2017 [citado em 14 dez 2020]; 18(6):710-11. Disponível em: http://periodicos.ufc.br/rene/article/view/31068/ 71659 
5 - Entringer AP, Pinto M, Dias MAB, Gomes MASM. Análise de custo-efetividade do parto vaginal espontâneo e da cesariana eletiva para gestantes de risco habitual no Sistema Único de Saúde. Cad Saúde Pública 2018 [citado em 14 dez. 2020]; 34(5):1-15. Disponível em: https://www.scielo.br/pdf/csp/v34n5/1678-4464csp-34-05-e00022517.pdf

6 - Garcia LV, Teles JM, Bonilha ALL. O centro de parto normal e sua contribuição para atenção obstétrica e neonatal no Brasil. REAS 2017 [citado em 14 dez 2020]; 7:356-63. Disponivel em: http://hdl.handle.net/10183/170557

7 - Reis TLR, Padoin SMM, Toebe TFP, Paula CC, Quadros JS. Autonomia feminina no processo de parto e nascimento: Revisão integrativa da literatura. Rev Gaúcha Enferm. 2017 [citado em 14 dez. 2020]; 38(1):1-8. Disponível em: https://www.scielo.br/pdf/rgenf/v38n1/01026933-rgenf-1983-144720170164677.pdf

8 - Martins CA, Mattos DV, Santos HFL. Autonomia da mulher no processo parturitivo. Rev Enferm UFPE 2016 [citado em 14 dez 2020]; 10(12):4509$16 . \quad$ Disponível em: https://periodicos.ufpe.br/revistas/revistaenferm agem/article/download/11517/13403

9 - Ferreira LS, Santos AF, Bezerra IP, Alves DA, Damasceno SS, Figueiredo ME, et al. Assistência de enfermagem durante o trabalho de parto e parto: A percepção da mulher. Rev Cuba Enferm. 2017 [citado em 14 dez 2020]; 33(2). Disponível en: http://www.revenfermeria.sld.cu/index.php/enf/a $\underline{\text { rticle/view/1102 }}$

10 - Kleinman A. Concepts and a model for the comparison of medical systems as cultural systems. Soc Sci Med. 1978;12(2B):85-95. DOI: $\underline{10.1016 / 0160-7987(78) 90014-5}$

11 - Bardin L. Análise de conteúdo. Lisboa: Edições 70; 2011.

12 - Coxon K. Birth place decisions: Information for women and partners on planning where to give birth. 2014 [citado em 14 dez 2020]. Disponível em:

https://kclpure.kcl.ac.uk/portal/files/33242518/Bi rth_place decision_support_Generic 2 2.pdf

13 - Lansky S, Souza KV, Morais ER, Oliveira BF, Diniz S, Viera NF, et al. Violência obstétrica:
Influência da Exposição Sentidos do Nascer na vivência das gestantes. Cien Saude Coletiva 2018;24(8):2811-24. DOI: 10.1590/1413$\underline{81232018248.30102017}$

14 - Dahlberg U, Persen J, Skogås AK, Selboe ST, Torvik HM, Aune I. How can midwives promote a normal birth and a positive birth experience? The experience of first-time Norwegian mothers. Sex Reprod Healthc. 2016;7:2-7. DOI: 10.1016/j.srhc.2015.08.001

15 - Sandall J, Soltani H, Gates S, Shennan A, Devane D. Midwife-led continuity models versus other models of care for childbearing women. Cochrane Database Syst Rev. 2016;28(4):CD004667. DOI: 10.1002/14651858.CD004667.pub5

16 - Vargens OMC, Silva ACV, Progianti JM. Contribuição de enfermeiras obstétricas para consolidação do parto humanizado em maternidades no Rio de Janeiro-Brasil. Esc Anna Nery 2017;21(1):1-8. DOI: 10.5935/1414$\underline{8145.20170015}$

17 - Carmo Leal MC. Parto e nascimento no Brasil: Um cenário em processo de mudança. Cad Saúde Pública 2018 [citado em 14 dez 2020]; 34(5):1-3. Disponível em: https://www.scielo.br/pdf/csp/v34n5/1678-4464csp-34-05-e00063818.pdf

18 - Pereira RM, Fonseca GO, Pereira ACCC, Gonçalves GA, Mafra RA. Novas práticas de atenção ao parto e os desafios para a humanização da assistência nas regiões sul e sudeste do Brasil. Cien Saude Coletiva 2018;23(11):3517-24. DOI: 10.1590/1413-812320182311.07832016

19 - Oliveira VJ, Penna CMM. Cada parto é uma história: Processo de escolha da via de parto. Rev Bras Enferm. 2018;71(supl 3):1228-36. DOI: 10.1590/0034-7167-2016-0497

20 - Tostes NA, Seidl EMF. Expectativas de gestantes sobre o parto e suas percepções acerca da preparação para o parto. Temas Psicol. 2016;24(2):681-93. DOI: 10.9788/TP2016.2-15

21 - Mouta RJO, Silva TMA, Melo PTS, Lopes NS, Moreira VA. Plano de parto como estratégia de empoderamento feminino. Rev Baiana Enferm. 2017;31(4):1-10. DOI: 10.18471/rbe.v31i4.20275 
22 - Carvalho SS, Cerqueira RFN. Influência do pré natal na escolha do tipo de parto: Revisão de literatura. Rev Aten Saúde 2020;18(63):120-8. DOI: $\underline{10.13037 / \mathrm{ras} . v o l 18 n 63.6315}$

23 - Santos FSR, Souza PA, LanskI S, Oliveira BJ, Matozinhos FP, Abreu ALN, Souza KV, et al. Os significados e sentidos do plano de parto para as mulheres que participaram da Exposição Sentidos do Nascer. Cad Saúde Pública 2019;35(6):1-11. DOI: $\underline{10.1590 / 0102-311 \times 00143718}$

24 - Pinheiro GQ, Silva Júnior AP, Giotto AC. O processo de parto: A importância do enfermeiro no parto humanizado. Rev Inic Cient Ext. 2019 [citado em 19 mar 2021]; 2(4):190-5. Disponível em: https://revistasfacesa.senaaires.com.br/index.php iniciacao-cientifica/article/view/255

25 - Oliveira M, Elias EA, Oliveira SR. Mulher e parto: Significados da violência obstétrica e a abordagem de enfermagem. Rev Enferm UFPE 2020;14:e243996 DOI: $\quad \underline{10.5205 / 1981-}$ $\underline{8963.2020 .243996}$

26 - Serres WP, Pieszak GM, Gomes GC, Prates LA, Rodrigues AP. Vivências de mulheres com o parto domiciliar: resgate por meio da história oral. Rev Enferm UFSM 2020;10(51):1-18. DOI: $\underline{10.5902 / 217976923484}$
Nota: Este documento é parte do relatório de Dissertação de Mestrado apresentada ao Curso de Pós-Graduação em Enfermagem da Escola de Enfermagem da Universidade Federal de Minas Gerais.

Recebido em: 07/12/2020

Aprovado em: $23 / 03 / 2021$ 